much work has been don $\theta$ on experimental tuberculosis in mice. Miss Betty Croshaw (Boot's, Nottingham) dealt with attempts to standardize the screening test in mice using intracerebral infection, all results being based on the extent of lung tuberculosis when the experiments were deliberately terminated four to six weeks after infection. Miss Croshaw's paper also dealt with the virulence of cultures according to the type of culture medium used and the advantage of objective interpretation of drug activity (that is, survival-time).

A note on the bacteriology of yoghurt was given by Miss E. R. Hiscox (Reading). It would appear that this fermented milk consists primarily of a mixture of Lactobacillus bulgaricus and Streptococcus thermophilus. In some types yeasts may also be present.

Miss C. M. Cousins (Milton-Deosan, London) described a preliminary screening test (bacteriological) for quaternary ammonium compounds and formulations. The test is based on a plate count method which determines the survival of a given test organism, Bacterium coli, in sterile homogenized whole milk, added with the bacterial suspension to the quaternary ammonium compound dilutions, for an exposure time of two minutes. The paper directed attention to the special cleaning of glassware that is necessary. The preparation and use of the quaternary ammonium compound inhibitor, lecithin in 'Lissapol $N^{\prime}$, was described, with details of the testing procedure. Examples quoted showed how this test indicates a difference in bactericidal efficiency between $(a)$ two different quaternary ammonium compound solutions, and $(b)$ the same quaternary ammonium compound included in two powder formulations of differing $p H$ value.

\section{GENES AND MUTATIONS}

$\mathrm{T}$ HE Symposia on Quantitative Biology held annually in the Biological Laboratory at Cold Spring Harbor, Long Island, have become a major ovent in biology. Their purpose is to foster a closer relationship between biology and the other basic sciences, and they set out to achieve this not only by attempting a synthesis of existing experimental data concerning a particular subject, but also by applying new knowledge gained in other fields.

This year, the sixteenth of the series, the topic of discussion, selected by Dr. M. Demerec (Carnegie Institution), was "The Genes and Mutations". The same subject was discussed ten years ago, and the present meeting was intended to show the advances made in genetical research during the past decade. In 1941 the main subjects of discussion were the giant chromosomes of the salivary glands of Drosophila, the mechanism of chromosome coiling and spiralization, and the quantitative aspect of spontaneous and radiation-induced mutations. Only one contribution was concerned with the genetical usefulness of microorganisms, viruses and bacteria. During the present Symposium the latter occupied a prominent position, and it was clearly demonstrated that the knowledge gained from studies of the genetical behaviour of bacteria, viruses and bacteriophage has deepened our understanding of the basic fundamentals of genetics themselves, and explained phenomena which baffled geneticists of ten years ago-as was so dramatically illustrated by T. M. Sonneborn (Indiana University) in the closing session.
A new theory of the gene, including its action in development and its relation to otlier genes, was brought to light by the work of B. MeClintock (Carnegie Institution). She described very remark. able and complicated results on mutable genes in maize, which can be interpreted as due to transposition of minute pieces of chromatin from one position to another in the chromosome. The frequency of such transposition is itself under genic control, which findings emphasize the close integration or interrela. tionship of the gene complex. According to $\mathrm{R}$. Goldschmidt (Stanford University, Cal.) the gene in the chromosome represents a "field of action" closely integrated into one system, in which gene mutation is a consequence of rearrangements on a submicroscopic scale. L. Stadler (University of Missouri) presented results on spontaneous gene mutation in maize, and E. R. Lewis (California Institute of Technology) on pseudoallelism in Drosophila. Both contributions have shown how it is possible by exact and extremely detailed genetical analysis to obtain insight into the complexity of genic activity. The same point was emphasized by S. G. Stephens (University of North Carolina) in describing the diversification of individual genetic loci in the diploid and amphidiploid forms of Gossypium.

Gene action and gene-enzyme relationship was discussed by D. M. Bonner (Yale University) and N. H. Horowitz (California Institute of Technology) in Neurospora. It was argued that there are genes which control only one step in the synthesis of enzymes, but an example in the synthesis of nicotinic acid was also presented to show that the blockage can be incomplete.

The genetical impact of chemical agents on genes and chromosomes was but little known in 1941 . However, the present conference showed that the wealth of results obtained meantime in diverse organisms by the study of a great array of substances is not only impressive but also has widened our concept of mutagenesis itself and brought to light phenomena not observed previously. C. Auerbach (University of Edinburgh) pointed out the differences between chemically and $X$-ray induced mutations, by studying the mosaics in Drosophila, and emphasized the possibility of a delayed effect on the gene. Dr. Demerec described tests of various highly mutagenic compounds on the streptomycin-dependent mutant of E'scherichia coli, which is a particularly suitable object for studies of the influence of environmental factors on gene-stability. On this aspect more evidence was presented by A. Hollaender (Oak Ridge National Laboratory, 'Tenn.) and collaborators, showing that lack of oxygen is one of the factors which greatly reduces the mutagenic effect of chemical agents and ionizing radiations. M. Westergaard (Institute of Genetics, Copenhagen) described his 'back-mutation' test in Neurospora, which will prove to be a very useful and rapid method for the detection of chemical mutagens, and made an attempt to interpret the chemical basis of induced mutagenesis. The aspect presented by Westergaard linked up closely with the contribution of N. H. Giles (Yale University), who described the various mechanisms which may be responsible for the spontaneous reversions of biochemical mutants in Neurospora.

The visible effects of various chemical agents on the chromosomes of Allium and Vicia were described by A. Levan (Institute of Genetics, Lund), who demonstrated that different chromosome regions may exhibit a different degree of reactivity to a drug, 
suggesting that further investigation by genetical and cytological means may disclose specific affinities between certain chemical compounds and chromosome regions or even genes.

The broader evolutionary significance of mutagenesis was discussed by A. Gustafsson (Forest Research Institute of Sweden, Stockholm), who illustrated, with examples on barley, how new mutants produced artificially can be superior to the original type under different environmental conditions. W. L. Russell (Oak Ridge National Laboratory, Tenn.), by using an ingenious method of analysis, was able to present data obtained from about 85,000 mice, which show that the X-ray induced mutation-rate is at least fifteen times higher in this mammal than in Drosophila. Because of the great likelihood that man belongs more to the former than to the latter type in respect of radiation sensitivity, Russcll's data add to the problem of radiation hazards in man a very serious emphasis, which was stressed by Prof. H. J. Muller.

The genetic composition of a population is known to be under the influence of various factors, such as mutation, selection, rate of reproduction, etc. A. Novick and L. Szilard (University of Chicago) have described the 'chemostat', which makes the study of these factors possible in bacteria. It is an apparatus in which the medium is automatically replaced so that the various growth-limiting factors may be added at a slower or higher rate than the reproduction of the bacteria. These workers illustrated with experimental observations the usefulness of the chemostat in genetical investigation, the results obtained being similar to those of K. C. Atwood (Columbia University) and co-workers employing the more conventiunal method of genetical analysis.

The symposium devoted one session to the cytoplasmic constituents of heredity. P. L'Héritier (University of Paris) has proved that the sensitivity of Drosophila to carbon dioxide is due to a cytoplasmic factor, and closely resembles a virus-caused infection. He was able to show that by injecting extract from carbon dioxide-sensitive flies into resistant Drosophila, the latter 'acquired' carbon dioxide sensitivity. When the 'virus' or 'genoid' invades the germ-plasm, then the carbon dioxide sensitivity becomes a heritable property. L'Héritier favours the view that the 'genoids' have an internal origin. A more complex system of cytoplasmic inheritance was presented by B. Ephrussi (University of Paris) in yeast. He finds that the formation of large and small colonies, which differ also in the presence or absence of cytochromcoxidase, is due to a nuclear gene, inducing an instability in the cytoplasm. The latter can be influenced or affected by environmental factors, such as the presence of trypoflavin in the medium, when the incidence of small-colony formation increases enormously.

A large part of the Symposium was taken up with the genetics of bacteria and bacterial viruses. J. Lederberg (University of Wisconsin) and co-workers gave a detailed review of bacterial genetics, derived from experiments with $E$. coli, line K.12. Lederberg pointed out the complex system of linkage relationships of known genetic loci in this bacterium. The inherent difficulties of bacterial heredity wore further stressed by E. M. Witkin (Carnegie Institution), who analysed the method of segregation and recombination in multinucleate bacterial cells. The cytology of bacteria was presented by K. A. Bisset (University of Birmingham) and E. D. DeLamater (University of Pennsylvania). Their papers brought out the basic disagreements in the interpretation of the cytological phonomena, and further emphasized the difficulties of bacterial genetics.

The transformation of various morphological and serological types of pneumococci by deoxyribosenucleic acid extracted from particular mutants was reviewed by H. Ephrussi-Taylor (Institute of Genetics of the C.N.R.S., Paris), who presented new results suggesting that the 'old' genetic determinant is not only altered but is completely replaced by the 'transforming principle'. R. D. Hotchkiss (Rockefeller Institute of Medical Research) has induced penicillin-resistant pneumococci which have yielded another 'transforming principle' (deoxyribosenucleic acid), and was also able to show that by combining this with the morphological 'transforming deoxyribosenucleic acid' they 'segregate' independently. Another interesting case of transformation has been found by $\mathrm{N}$. Zinder (University of Wisconsin) in Salrronella, in which a 'stimulating' substance must be liberated first, in order to produce the transforming factor itself. It is claimed that the latter is associated with the microsomes of the cytoplasm.

The various propertios of bacterial viruses and their behaviour in heredity wore described by S. E. Luria (University of Illinois) and A. O. Hershey (Carnegie Institution). It has been shown that genetical analysis is still the most powerful method by which not only the characteristics but also the organization of the bacteriophage itself may be studied. At the same time it has been possible to demonstrate in these 'simple' forms many of the features of a complex genetic system, such as exists in higher organisms. However, they also show other phenomena, such as 'phenotypic mixing', which at present remain uxiexplained.

The Cold Spring Harbor Symposium was an outstanding success since it brought together into a coherent and closely integrated system a great deal of new and fundamental information, obtained from studies on the most diverse organisms. It has emphasized two facts : first, genetics is making use of many new organisms and techniques and is thus at prosent extending its boundaries extremely rapidly and to great profit; and secondly, and consequent upon the specialization which is necessarily occurring, it becomes increasingly desirable to hold meetings such as this, at which the new fields may be integrated.

\section{SECOND INTERNATIONAL CONGRESS ON ASTRONAUTICS}

THE second International Congress on Astronautics was held in London during September 3-8. It was attended by nearly fifty delegates representing societies and groups interested in astronautics from Argertina, Austria, France, Germany, Great Britain, Italy, Spain, Sweden, Switzerland and the United States. The first International Congress, held in Paris in September 1950, was purely exploratory in nature and was intended as a series of informal meetings to discuss the possibility of setting up an international federation. As a result of the deliberations of the first two days of the recent Congress, an International Astronautical Federation was founded, "to prorrote and stimulate the arhievement of spaceflight". Dr. Eugen Sänger was elected president, and the two vice-presidents are Dr. G. Loeser, of the Gesellschaft für Weltraumforschung, and Andrew G. 